\title{
Serum Paraoxonase Activity and Genotype Distribution in Japanese Patients with Diabetes Mellitus
}

\author{
Takenori SAKAI, Bunzou MATSUURA and Morikazu ONJI
}

\begin{abstract}
We investigated the serum paraoxonase (PON) activity and genotype distribution in 139 patients with non-insulin-dependent diabetes mellitus and in 240 control subjects in a Japanese population. There were no significant differences in PON genotype frequencies between the diabetic and control subjects, but the PON activity was significantly less in diabetic subjects $(\mathrm{p}<0.01)$. PON activity was significantly related to levels of total cholesterol and high density lipoprotein (HDL) cholesterol in the control subjects, but not in the diabetic subjects. In diabetic subjects with the genotype AA, the mean maximum intimal-medial thickness (IMT) of the carotid artery was significantly greater than in subjects with genotype AB or BB. PON may play an important role in the development of atherosclerosis associated with diabetes mellitus.

(Internal Medicine 37: 581-584, 1998)
\end{abstract}

Key words: non-insulin-dependent diabetes mellitus (NIDDM), atherosclerosis, intimal-medial thickness (IMT), high density lipoprotein (HDL) cholesterol, polymorphism of paraoxonase gene

\section{Introduction}

Paraoxonase [EC 3.1.8.1] is an high density lipoprotein (HDL)-associated esterase that hydrolyzes paraoxon (1). Many studies have indicated that the existence of a genetic polymorphism of paraoxonase is a determinant of its activity $(2,3)$. This polymorphism results from an amino acid substitution in the active site of the enzyme, giving rise to low- and high-activity isoform. The Gln192(A) isoform is not highly active toward paraoxon; in contrast, the $\operatorname{Arg} 192$ (B) isoform hydrolyzes paraoxon more rapidly. Previous studies in Caucasians have shown that patients with diabetes mellitus have reduced serum paraoxonase activity $(4,5)$, and that paraoxonase gene polymorphism is associated with a predisposition to coronary atherosclerosis $(6,7)$. This suggests that the decrease in the activity of serum paraoxonase associated with diabetes mellitus may play a role in the increased incidence of premature atherosclerosis associated with this disease.

In Caucasian populations, the frequency of the low activity phenotype and genotype seems to be high (8-10). In contrast, the frequency of the low activity phenotype seems to be low in ethnic groups such as Chinese, Filipinos and Dravidian Indians (11), and the relationship of paraoxonase and diabetes mellitus in these groups, as well as in Japanese, is unknown. Here, we investigate the serum paraoxonase activity and genotype distribution in Japanese patients with diabetes mellitus.

\section{Subjects and Methods}

\section{Subjects}

The control population consisted of 240 apparently healthy individuals not taking medication, who were present at a routine health check-up. The experiment population was made up of patients at the Third Department of Internal Medicine, Ehime University Hospital, and comprised 139 men and women with non-insulin-dependent diabetes mellitus (NIDDM). Diabetes mellitus was diagnosed according to the criteria of the Japan Diabetes Society. In our assessment of macroangiopathy, we took measurements of the mean maximum intimal-medial thickness (IMT) of the carotid artery by ultrasonography (12, 13). The imaging protocol involved obtaining a single longitudinal lateral view of the distal $10 \mathrm{~mm}$ of the right and left common carotid arteries. All subjects gave informed consent in accordance with the Helsinki Declaration.

\section{Laboratory measurements}

Venous blood samples were drawn after an overnight fast. Serum total cholesterol, HDL-cholesterol (HDL-C, measured

From the Third Department of Internal Medicine, Ehime University School of Medicine, Ehime

Received for publication May 15, 1997; Accepted for publication March 24, 1998

Reprint requests should be addressed to Dr. Takenori Sakai, the Third Department of Internal Medicine, Ehime University School of Medicine, Sitsukawa, Sigenobu-cho, Onsen-gun, Ehime 791-0295 
after the precipitation of lower density lipoproteins with phosphotungstate/ $\mathrm{MgCl}_{2}$ ), and triglyceride were enzymatically determined using an autoanalyzer (TBA-80S: Toshiba Inc., Tokyo). Plasma glucose concentration upon fasting was measured by the glucose oxidase method. Glycosylated hemoglobin (HbA1c) was measured by high performance liquid chromatography assay (Kyoto Daiichi Scientific Equipment Inc., Kyoto). The fructosamine (FRA) concentration was measured by nitrobluetetrazolium (NBT) reduction method with fructosamine assay kit II (Roche Japan, Tokyo). Serum C-peptide (CPR) concentration was measured by radioimmunoassay with the C-Peptide Test (Shionogi Research Laboratories, Osaka).

\section{Paraoxonase enzyme activity}

Paraoxonase activity was measured by adding serum to $1 \mathrm{ml}$ Tris- $\mathrm{HCl}$ buffer $(100 \mathrm{mmol} / l, \mathrm{pH} 8.5)$ containing $2 \mathrm{mmol} / l$ $\mathrm{CaCl}_{2}$ and $6.0 \mathrm{mmol} / \mathrm{l}$ paraoxon (Sigma Chemical Company, London). The generation of p-nitrophenol was measured at 405 $\mathrm{nm}$ and $37^{\circ} \mathrm{C}$ in a continuously recording spectrophotometer (Pharmacia Ultraspec III, Cambridge, England). A unit was defined as a $1 \mu \mathrm{mol}$ paraoxon hydrolyzed per minute under the above assay conditions (14).

\section{DNA analysis}

Paraoxonase was genotyped by restriction isotyping; the nucleotide substitution corresponding to position 192 (GlnArg) creates an Alw1 restriction site. White blood cells were isolated from blood and DNA extracted using standard procedures. A 99 base-pair fragment covering the region containing the mutation was amplified by polymerase chain reaction (PCR), with primers described by Humbert et al (3). It involved a primary amplification of 30 cycles with annealing at $61^{\circ} \mathrm{C}$. PCR products were digested with Alw1, separated by agarose gel (3\%) electrophoresis and visualized by use of ethidium bromide. Allele A (glutamine) corresponded to a 99 base pair fragment and allele B (arginine) to 65 and 34 base pair fragments (Fig. 1).

\section{Statistical analysis}

Values were expressed as mean \pm standard deviation (SD). All data except that for triglycerides were analyzed using the unpaired $t$-test, linear regression, and Scheffe test followed by one-way ANOVA. Triglycerides were analyzed by the MannWhitney U test and Kruskal-Wallis test. Categorical variables were compared between groups by use of the Chi-squared test and crude odds ratio. Allele frequencies were estimated by the gene-counting method, and Hardy-Weinberg's equilibrium was tested by the Chi-squared test. Significance was defined at $\mathrm{p}<0.05$.

\section{Results}

The diabetic subjects had a lower percentage of men and were on average older than the control subjects (Table 1). However, neither of these parameters was related to the serum paraoxonase activity or to genotype in either group of subjects

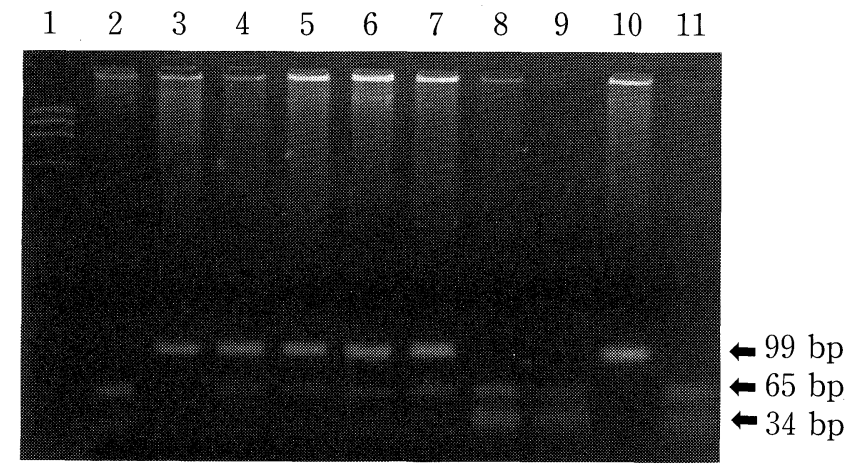

Figure 1. PCR-RFLP analysis of paraoxonase genotype. Lane 2, 8, 9, and 11 show the band patterns for the BB genotype. Lane 4, 5, 6, and 7 show the band patterns for the AB genotype. Lane 3 and 10 show the band patterns for the AA genotype. Lane 1 is $\phi 174$ Hind III digest.

Table 1. Demographic Details of the Populations Studied

\begin{tabular}{lcc}
\hline & Control $(\mathrm{n}=240)$ & NIDDM $(\mathrm{n}=139)$ \\
\hline Sex (male/female) & $179 / 61$ & $65 / 74^{* *}$ \\
Age $($ years $)$ & $48.0 \pm 8.70$ & $61.7 \pm 13.6^{* *}$ \\
FPG $(\mathrm{mmol} / l)$ & $5.82 \pm 0.77$ & $8.24 \pm 3.43^{* *}$ \\
HbA1c $(\%)$ & $\mathrm{ND}$ & $7.5 \pm 1.9$ \\
Fructosamine $(\mu \mathrm{mol} / l)$ & $\mathrm{ND}$ & $353 \pm 78.7$ \\
C-peptide $(\mathrm{nmol} / l)$ & $\mathrm{ND}$ & $0.73 \pm 0.44$ \\
Total cholesterol $(\mathrm{mmol} / l)$ & $5.02 \pm 0.90$ & $5.05 \pm 0.98$ \\
Triglyceride $(\mathrm{mmol} / l)$ & $1.47 \pm 0.91$ & $1.51 \pm 1.01$ \\
HDL cholesterol $(\mathrm{mmol} / l)$ & $1.40 \pm 0.38$ & $1.32 \pm 0.46$ \\
\hline
\end{tabular}

HbAlc: glycosylated hemoglobin, FPG: fasting plasma glucose, ND: not determined, NIDDM: non-insulin-dependent diabetes mellitus. Values are mean \pm SD. ${ }^{* *} \mathrm{p}<0.01$ significantly different from control subjects.

(data not shown).

The gene frequencies in control subjects were 0.31 for allele A with low activity and 0.69 for allele B with high activity. In diabetic subjects, the allele $A$ frequency was 0.33 and the allele $B$ frequency was 0.67 . There were no significant differences in the gene frequencies between diabetic and control subjects (Table 2). In both groups, the paraoxonase activity was highest in genotype $\mathrm{AA}$, lower in genotype $\mathrm{AB}$, and lower still in $\mathrm{BB}$. Furthermore, the paraoxonase activity was significantly lower in the diabetic subjects of every genotype except genotype AA (Table 3). Paraoxonase activity was significantly related to the levels of total cholesterol and HDL-C in control subjects, but this was not true in diabetic subjects. Triglycerides were not related to paraoxonase activity in either group (Table 4).

In diabetic subjects, paraoxonase activity was not significantly associated with fasting plasma glucose (FPG), HbAlc, FRA, or CPR (Table 5). In an investigation of clinical parameters with different genotypes, the IMT of carotid arteries in 


\section{Paraoxonase in NIDDM}

subjects with the genotype $\mathrm{AA}$ were significantly greater than in those with genotypes $\mathrm{AB}$ and $\mathrm{BB}$ (Table 6).

Table 2. Paraoxonase Genotype Distributions in Control and Diabetic Subjects

Control $(n=240) \quad$ NIDDM $(n=139)$

\begin{tabular}{lrr}
\hline Genotype distribution $(\%)^{\#}$ & & \\
AA & $24(10.0)$ & $14(10.1)$ \\
AB & $102(42.5)$ & $63(45.3)$ \\
BB & $114(47.5)$ & $62(44.6)$ \\
Gene frequency $^{\# \#}$ & & \\
A & 0.31 & 0.33 \\
B & 0.69 & 0.67
\end{tabular}

AA: a homozygous low activity genotype, $A B$ : a heterozygous genotype, BB: a homozygous high activity genotype, NIDDM: non-insulin-dependent diabetes mellitus. ${ }^{*} \chi^{2}=0.321, \mathrm{p}=0.852$, ${ }^{\#} \mathrm{p}=0.711$.

Table 3. Paraoxonase Activity in Control and Diabetic Subjects

\begin{tabular}{|c|c|c|c|}
\hline & Control $(n=240)$ & NIDDM (n=139) & \\
\hline Paraoxonase activity (U/l) & $568.8 \pm 208.3$ & $437.5 \pm 170.3 * *$ & \\
\hline genotype AA & $249.0 \pm 41.17$ & $215.9 \pm 73.77$ & \\
\hline $\mathrm{AB}$ & $478.3 \pm 124.2$ & $\# \quad 382.3 \pm 110.8$ & \# \\
\hline $\mathrm{BB}$ & $717.0 \pm 162.4-$ & $543.6 \pm 161.6-$ & \\
\hline
\end{tabular}

AA: a homozygous low activity genotype, AB: a heterozygous genotype, BB: a homozygous high activity genotype, NIDDM: non-insulin-dependent diabetes mellitus. Values are mean $\pm \mathrm{SD}$. ${ }^{*} \mathrm{p}<0.01$ significantly different from control subjects. $\# \mathrm{p}<0.01$ significantly different among genotype $\mathrm{AA}, \mathrm{AB}$ and $\mathrm{BB}$.

\section{Discussion}

To the authors' knowledge, this is the first report of paraoxonase gene frequencies in a Japanese population, and our findings indicate a higher frequency of allele B with high activity than has been found in Caucasian populations (8-10).

Table 4. Linear Regression of Paraoxonase Activity and Serum Lipid

\begin{tabular}{lcccc}
\hline & \multicolumn{2}{c}{ Control } & \multicolumn{2}{c}{ NIDDM } \\
& $\mathrm{R}$ & $\mathrm{P}$ & $\mathrm{R}$ & $\mathrm{P}$ \\
\hline Total cholesterol & 0.196 & 0.002 & 0.042 & 0.626 \\
Triglyceride & 0.008 & 0.899 & 0.056 & 0.516 \\
HDL cholesterol & 0.177 & 0.006 & 0.005 & 0.955 \\
\hline
\end{tabular}

NIDDM: non-insulin-dependent diabetes mellitus.

Table 5. Linear Regression of Paraoxonase Activity and Laboratory Measurement in Diabetic Subjects

\begin{tabular}{lcc}
\hline & $\mathrm{R}$ & $\mathrm{P}$ \\
\hline FPG & 0.053 & 0.537 \\
Fructosamine & 0.072 & 0.401 \\
HbA1c & 0.082 & 0.335 \\
C-peptide & 0.038 & 0.655 \\
\hline
\end{tabular}

FPG: fasting plasma glucose, HbA1c: glycosylated hemoglobin.

Table 6. Clinical Data in Diabetic Subjects with Different Genotypes

\begin{tabular}{lrccc}
\hline & & AA $(\mathrm{n}=14)$ & AB $(\mathrm{n}=63)$ & BB $(\mathrm{n}=62)$ \\
\hline Age & (years) & $62.6 \pm 13.5$ & $60.4 \pm 13.3$ & $62.5 \pm 14.1$ \\
Sex & $($ male/female $)$ & $5 / 9$ & $32 / 31$ & $37 / 25$ \\
BMI & $\left(\mathrm{kg} / \mathrm{m}^{2}\right)$ & $23.1 \pm 4.2$ & $24.7 \pm 4.8$ & $21.7 \pm 6.0$ \\
Smokers & $($ yes $/ \mathrm{no})$ & $6 / 8$ & $36 / 27$ & $40 / 22$ \\
Hypertension & $($ yes $/ \mathrm{no})$ & $8 / 6$ & $40 / 23$ & $35 / 27$ \\
Diabetes duration & $($ years $)$ & $11.4 \pm 12.5$ & $11.7 \pm 6.7$ & $13.2 \pm 9.1$ \\
FPG & $(\mathrm{mmol} / l)$ & $9.14 \pm 3.93$ & $8.50 \pm 3.55$ & $7.77 \pm 3.17$ \\
HbAlc & $(\%)$ & $7.52 \pm 2.07$ & $7.57 \pm 1.90$ & $7.49 \pm 1.92$ \\
C-peptide & $(\mathrm{nmol} / l)$ & $0.70 \pm 0.43$ & $0.70 \pm 0.33$ & $0.77 \pm 0.53$ \\
Total cholesterol & $(\mathrm{mmol} / l)$ & $4.84 \pm 1.15$ & $5.20 \pm 0.93$ & $4.95 \pm 0.99$ \\
Triglyceride & $(\mathrm{mmol} / l)$ & $1.22 \pm 0.43$ & $1.64 \pm 1.27$ & $1.45 \pm 0.76$ \\
HDL-cholesterol & $(\mathrm{mmol} / l)$ & $1.27 \pm 0.71$ & $1.27 \pm 0.40$ & $1.38 \pm 0.45$ \\
IMT & $(\mathrm{mm})$ & $0.89 \pm 0.38^{*}$ & $0.72 \pm 0.17$ & $0.74 \pm 0.18$ \\
& & & &
\end{tabular}

AA: a homozygous low activity genotype, $\mathrm{AB}$ : a heterozygous genotype, $\mathrm{BB}$ : a homozygous high activity genotype, BMI: body mass index, FPG: fasting plasma glucose, HbA1c: glycosylated hemoglobin, IMT: intimal-medial thickness of carotid artery. ${ }^{*} \mathrm{p}<0.05$ compared with genotype $\mathrm{AB}$ and $\mathrm{BB}$. 
These frequencies are close to those observed in other Asian ethnic populations (11). Our results show that diabetic patients in the Japanese population have reduced serum paraoxonase activity similar to that in the Caucasian population $(4,5)$. This suggests that the decrease in the activity of serum paraoxonase associated with diabetes is not related to genotype distribution. The cause of the lower paraoxonase activity in diabetic patients is unknown, and further experiments are necessary. Paraoxonase is believed to be anchored to the HDL lipids by its hydrophobic $\mathrm{N}$-terminal end (14). However, the absence of a correlation between paraoxonase activity and HDL cholesterol suggests that the lower paraoxonase activity in diabetes is caused by factors other than the lower HDL cholesterol level. Furthermore, the glycation, or nonenzymatic glycosylation, of several structural and functional proteins has been described previously $(15,16)$. Glycation often leads to alterations in the conformation and/or function of proteins $(17,18)$. Paraoxonase activity may be altered as a result of glycation of the protein itself or of HDL. In this cross-study, paraoxonase activity was not significantly associated with glycosylated hemoglobin or fructosamine, but this hypothesis cannot be denied.

The clinical importance of the lower paraoxonase activity in diabetes is unknown. Significant associations were not found between the paraoxonase activity and diabetic microangiopathy (data not shown), but we observed significant differences in IMT among the genotypes. IMT in diabetic patients was significantly greater than in age-matched control subjects $(0.77 \pm 0.21$ vs $0.68 \pm 0.18 ; \mathrm{p}<0.01)$. In genotype AA, IMT was significantly greater than in genotypes $\mathrm{AB}$ and $\mathrm{BB}$. However, other parameters which are known risk factors for atherosclerosis, such as age, sex, serum total cholesterol, prevalence of hypertension, and smoking were no different among the genotypes. This suggests that the decrease in the activity of serum paraoxonase in diabetes may play a role in the increased incidence of premature atherosclerosis associated with this disease. Two previous studies in patients with coronary heart disease found an increased frequency of the genotype $B(6,7)$, but there are no detailed studies showing that genotype B seems to be a high activity phenotype that is a risk factor for atherosclerosis. In the present study, we have no explanation for the discrepancy between our findings and those of the two previous studies. A recent study of Finns by Antikainen et al (19) concluded that the paraoxonase gene polymorphism Gln-Arg192 is not associated with a predisposition to coronary atherosclerosis. We therefore think that the explanation for the discrepancy is at the population level, or is related to genetic heterogeneity within or between our study group. Furthermore, paraoxonase in vitro seemed to have the capacity to hydrolyze at least some of the products of lipid peroxidation, and under experimental conditions it was able to decrease the extent to which low density lipoprotein (LDL) is oxidized (20). This finding suggests that individuals with a low paraoxonase activity phenotype may have a greater risk than those with high-activity phenotypes of developing a disease such as atherosclerosis, which may involve lipid peroxidation.

\section{References}

1) Mackness MI, Walker $\mathrm{CH}$. Partial purification and properties of sheep serum 'A'-esterases. Biochem Pharmacol 32: 2291, 1983.

2) Furlong CE, Richter RJ, Seidel SL, Motulsky AG. Role of genetic polymorphism of human plasma paraoxonase/arylesterase in hydrolysis of the insecticide metabolites chlorpyrifos oxon and paraoxon. Am JHum Genet 43: 230, 1988.

3) Humbert R, Adler DA, Disteche CM, Hassett C, Omiecinski CJ, Furlong $\mathrm{CE}$. The molecular basis of the human serum paraoxonase activity polymorphism. Nat Genet 3: 73, 1993.

4) Mackness MI, Harty D, Bhatnagar D, et al. Serum paraoxonase activity in familial hypercholesterolaemia and insulin-dependent diabetes mellitus. Atherosclerosis 86: 193, 1991.

5) Abbott CA, Mackness MI, Kumar S, Boulton AJ, Durrington PN. Serum paraoxonase activity, concentration, and phenotype distribution in diabetes mellitus and its relationship to serum lipids and lipoproteins. Arterioscler Thromb Vasc Biol 15: 1812, 1995.

6) Ruiz J, Blanche H, James RW, et al. Gln-Arg192 polymorphism of paraoxonase and coronary heart disease in type 2 diabetes. Lancet 346: $869,1995$.

7) Serrato M, Marian AJ. A variant of human paraoxonase/arylesterase (HUMPONA) gene is a risk factor for coronary artery disease. J Clin Invest 96: 3005, 1995.

8) Eiberg H, Mohr J. Genetics of paraoxonase. Ann Hum Genet 45: 323, 1981.

9) Geldmacher-von Mallinckrodt M, Diepgen TL, Duhme C, Hommel G. A study of the polymorphism and ethnic distribution differences of human serum paraoxonase. Am J Phys Anthropol 62: 235, 1983.

10) Mueller RF, Hornung S, Furlong CE, Anderson J, Giblett ER, Motulsky AG. Plasma paraoxonase polymorphism: a new enzyme assay, population, family, biochemical, and linkage studies. Am J Hum Genet 35: 393, 1983.

11) Roy AC, Saha N, Tay JS, Ratnam SS. Serum paraoxonase polymorphism in three populations of southeast Asia. Hum Hered 41: 265, 1991.

12) Wei M, Gonzalez C, Haffner SM, O'Leary DH, Stern MP. Ultrasonographically assessed maximum carotid artery wall thickness in Mexico City residents and Mexican Americans living in San Antonio, Texas. Association with diabetes and cardiovascular risk factors. Arterioscler Thromb Vasc Biol 16: 1388, 1996.

13) Wendelhag I, Gustavsson T, Suurkula M, Berglund G, Wikstrand J. Ultrasound measurement of wall thickness in the carotid artery: fundamental principles, and description of a computerized analysing system. Clin Physiol 11: 565, 1991.

14) Furlong CE, Costa LG, Hassett C, et al. Human and rabbit paraoxonase: purification, cloning, sequencing, mapping and role of polymorphism in organophosphate detoxication. Chem Biol Interact 87: 35, 1993.

15) Reiser KM, Amigable MA, Last JA. Nonenzymatic glycation of type 1 collagen. The effects of aging on preferential glycation sites. J Biol Chem 267: 24207, 1992.

16) Beswick HT, Harding JJ. Conformational changes induced in lens alphaand gamma-crystallins by modification with glucose 6-phosphate. Implications for cataract. Biochem J 246: 761, 1987.

17) Arai K, Maguchi S, Fujii S, Ishibashi H, Oikawa K, Taniguchi N. Glycation and inactivation of human $\mathrm{Cu}-\mathrm{Zn}$-superoxide dismutase. Identification of the in vitro glycated sites. J Biol Chem 262: 16969, 1987.

18) Vlassara $H$, Brownlee $M$, Cerami A. Nonenzymatic glycosylation: role in the pathogenesis of diabetic complications. Clin Chem 32: B37, 1986.

19) Antikainen M, Murtomaki S, Syvanne M, et al. The Gln-Arg 191 polymorphism of the human paraoxonase gene (HUMPONA) is not associated with the risk of coronary artery disease in Finns. J Clin Invest 98: 883, 1996.

20) Mackness MI, Durrington PN. High density lipoprotein, its enzymes and their potential to influence lipid peroxidation. Atherosclerosis 115: 243, 1995. 